\title{
A preliminary study on forming limit diagram and strain distribution of ASS 304
}

\author{
A. Anitha Lakshmi ${ }^{1}$, Ch. Srinivasa Rao ${ }^{2}$, J. Gangadhar ${ }^{3}$, Swadesh Kumar Singh ${ }^{4}{ }^{*}$ \\ 1, 3, 4 Department of Mechanical Engineering, GRIET, Hyderabad, AP, India-500090 \\ 2. Department of Mechanical Engineering, Andhra University, Visakhapatnam, AP, India-530003
}

\section{Index Terms}

ASS-304

Hemispherical Punch Test

Strain Distribution

Formability

Biaxial Strain

Received: 26 May 2016

Accepted: 11 June 2016

Published: 26 April 2016

\begin{abstract}
Forming limit diagrams (FLDs) are constructed to describe the strain rates at which a highly localized zone of thinning or necking becomes visible on the surface of sheet metal. Austenitic Stainless Steel (ASS) 304 sheets are increasingly used for making different parts because of their high corrosion-resistivity, good appearance, and superior formability. However, the austenitic phase gets transformed into martensite during forming, revealing its highly unstable nature. This preliminary study investigates the formability and behavior of ASS 304 by plotting forming limit diagram, strain distribution, limiting dome height, and forming ratio. It is shown that enhancement of formability is largest on the biaxial side of the FLD because the fraction martensite transformed depends on the thickness strain. Future work on the formability of ASS 304 is also discussed.
\end{abstract}

(C) 2016 The Author(s). Published by TAF Publishing.

\section{INTRODUCTION}

Austenitic Stainless Steel 304 (ASS 304) sheets are increasingly used for making different parts because of their high corrosion-resistivity, good appearance and superior formability [1], [3]. Forming processes are commonly used in the industry because it eradicates costly operations such as welding, machining and manufactures parts with reduced weight and good mechanical properties with high production rates [4]. Stretching and Deepdrawing processes are popularly used to assess the formability of sheet metals [5]. The popular commercial applications for ASS 304 are architectural trim appliances, chemical equipment, dairy equipment, kitchen equipment, food handling equipment, marine, sanitary fittings,

\footnotetext{
* Corresponding author: Swadesh Kumar Singh

E-mail: swadeshsingh@griet.ac.in
}

shipping drums, chemical processing, paper industry, pressure vessels and pharmaceutical equipment. [6].

Cold forming of ASS-304 increases martensite transformation due to the accumulated strain in forming process and brings the rise in working force, the decrease in corrosion resistivity, the magnetization and the delayed cracking [6]. The transformation of the austenitic phase to martensite is a function of strain, strain rate and temperature [7]. To avoid the martensitic transformations and omit the annealing process, warm forming is useful, since the martensitic transformation decreases with increasing temperature [8].

The behavior and formability of stainless steel sheet during warm forming was also the subject of a number of studies. Takuda et al. [8] performed warm cup drawing experiments for an austenitic stainless steel and examined the distribution of martensite content in the specimens after the tests. Iguchi and Ujiro [9] investigated the effect 
of the temperature gradient on the stretch-formability of a ferritic stainless steel in stamping.

Despite the large applications of ASS 304 in the industry, there is still a lack of understanding about its formability at warm conditions. In the present article, hemispherical punch tests have been conducted at room temperature to evaluate formability of ASS-304.

\section{EXPERIMENTAL SETUP AND METHODOLOGY}

In this work, ASS-304 sheet of $1.0 \mathrm{~mm}$ thickness is used. The composition of the employed material is given in Table 1. the grid marked samples to onset of localized necking or to

stages-grid marking the sheet samples, punch stretching

1. The experimental procedure mainly involves three failure and measurement of strains. Grid marking on the sheet samples of ASS-304 was done using a non-contacting grid of $5 \mathrm{~mm}$ diameter circles. The grid pattern was printed on sheet samples using electro-chemical grid marking technique. Punch stretching experiments were conducted upto necking or fracture of the cup/dome using suitably designed and fabricated tools (punch, upper and lower dies) on a $40 \mathrm{~T}$ capacity single action hydraulic press. A $50 \mathrm{~mm}$ diameter hemispherical punch fabricated on a numerically controlled machine was used in this study. The different strain rates (tension-tension, plane strain and tension compression during punch stretching) were obtained by varying the width of the samples (between 10 and $110 \mathrm{~mm}$ insteps of $20 \mathrm{~mm}$ ). A draw bead of $72 \mathrm{~mm}$ diameter was provided on the dies to restrict the material flow from outside. Sufficient blank holding pressure was applied using the upper die to clamp the material in the draw bead using a blank holder.

TABLE 1

MATERIAL COMPOSITION FOR ASS-304 (\%WT)

\begin{tabular}{ccccccccccc}
\hline \hline Element & $\mathrm{Fe}$ & $\mathrm{C}$ & $\mathrm{Mn}$ & $\mathrm{Si}$ & $\mathrm{Mo}$ & $\mathrm{Co}$ & $\mathrm{Cr}$ & $\mathrm{Cu}$ & $\mathrm{Ni}$ & Others \\
\hline ASS 304 & 70.780 & 0.025 & 1.140 & 0.410 & 0.360 & 0.210 & 18.400 & 0.180 & 8.190 & 0.305 \\
\hline \hline
\end{tabular}

TABLE 2

MATERIAL PROPERTIES OF ASS 304 AT VARIOUS TEMPERATURES

\begin{tabular}{lcccccc}
\hline \hline \multicolumn{1}{c}{ Temp. $\left({ }^{\circ} \mathrm{C}\right)$} & $\begin{array}{c}E \\
(\mathrm{GPa})\end{array}$ & $n$ & $\begin{array}{c}K \\
(\mathrm{MPa})\end{array}$ & $\mathrm{R}_{0}$ & $\mathrm{R}_{45}$ & $\mathrm{R}_{90}$ \\
& 203 & 0.387 & 1414 & 0.87 & 1.24 & 1.08 \\
\hline Room Temp. & 167 & 0.435 & 1299 & 0.64 & 2.24 & 1.16 \\
$150^{\circ} \mathrm{C}$ & 141 & 0.458 & 1136 & 0.91 & 1.24 & 0.68 \\
$300^{\circ} \mathrm{C}$ & & & & & & \\
\hline \hline
\end{tabular}

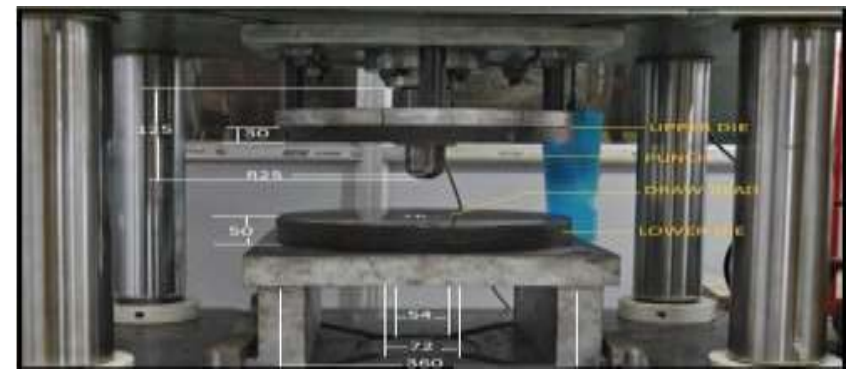

Fig.1. 40T capacity single action hydraulic press

For each blank width, four to five specimens were tested to get maximum number of data points. The circles on the sheet samples became ellipses after deformation falling into safe, necked and failed zone were determined by 
measuring major diameter and minor diameter of ellipses in both longitudinal and transverse directions of the sample using a microscope. The forming limiting curve was drawn clearly demarcating the safe limiting strains from the unsafe zone containing the necked and fractured ellipse the major strain versus minor strain.

To represent the strain distribution in the punch strain distribution in the punch stretched samples with different strain rates the major and minor strains were measured for all the ellipses along the longitudinal direction of all the ellipses, along the longitudinal direction of the samples and lying at the centre of the blank which represent the radius and tangential strains in the samples at these locations. The centre of the ellipse is referred to as the pole. The radial and tangential strains were plotted as a function of their distance from the pole.

\section{FINITE ELEMENT ANALYSIS}

The FE analysis is done using a commercially available software DYNAFORM version 5.6.1 with LS-DYNA version 971 solver. The input model consisting of die, blank, blank holder and punch has been constructed in pre-processor. The punch, die and blank holder have been considered as rigid body in the FE analysis of deep drawing process. The fine meshing has been done on the surface of die, bank holder and punch. Blank has been considered as a deformable body and undergoes excessive deformation in deep drawing process. Therefore, adaptive meshing has been used for the blank material. The blank and the tool components have been meshed using Belytschko-Tsay shell elements as it takes less computational time, around $30-50 \%$ less than others. Selective mass scaling has been used for FE simulations. The developed material model Barlat 1989 has been assigned to blank material.

The accuracy of FE analysis in sheet metal forming is significantly dependent on selection of friction coefficient value. It is very difficult to calculate friction coefficient value experimentally.

Inverse approach is one of the commonly used approaches to determine friction coefficient value using FE analysis. The methodology has been adopted by varying the coefficient of friction values and superimposing experimental and simulated plot of punch load vs. punch displacement. Friction coefficients are selected to be 0.09 for punch and 0.125 for die and blank holder.

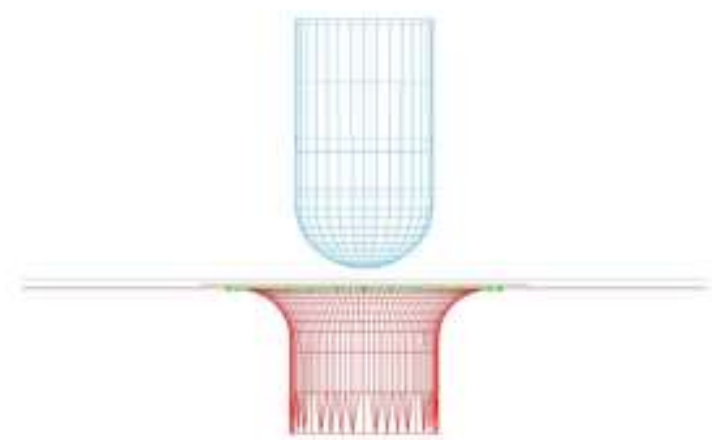

Fig. 2. Finite element model of stretch forming setup

The complete FE models for stretching process are shown in Figure 2. LDH in simulation is calculated by considering frames to the point where strain data start appearing in the necking region.

Results and Discussion:

3.1 Forming limit diagram:

The formed blanks of different widths and the sheets shown in Figure. 3 were obtained by conducting punch stretching experiments on specimens of different widths as explained earlier. Because of the large scatter in the measured strains with varying blank width and also due to the overlap of some points, it is difficult to draw a very precise curve that indicates the onset of failure. A forming limit curve drawn is shown in Figure.4 separating the necked and safe region.

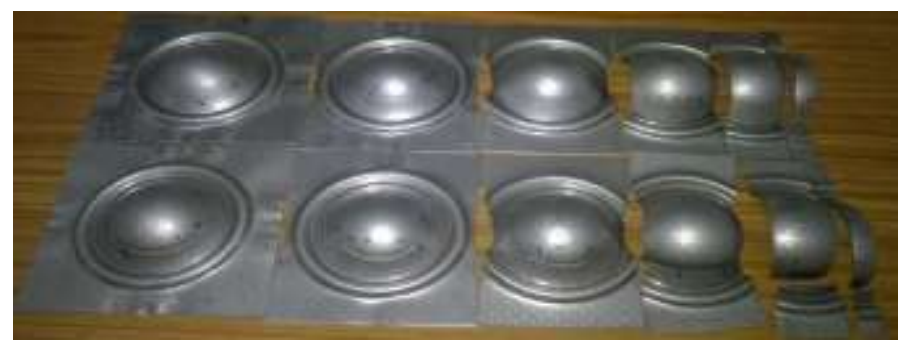

Fig. 3. Representative punch stretch test cups showing necking and fracture at room temperature for all specimen widths 


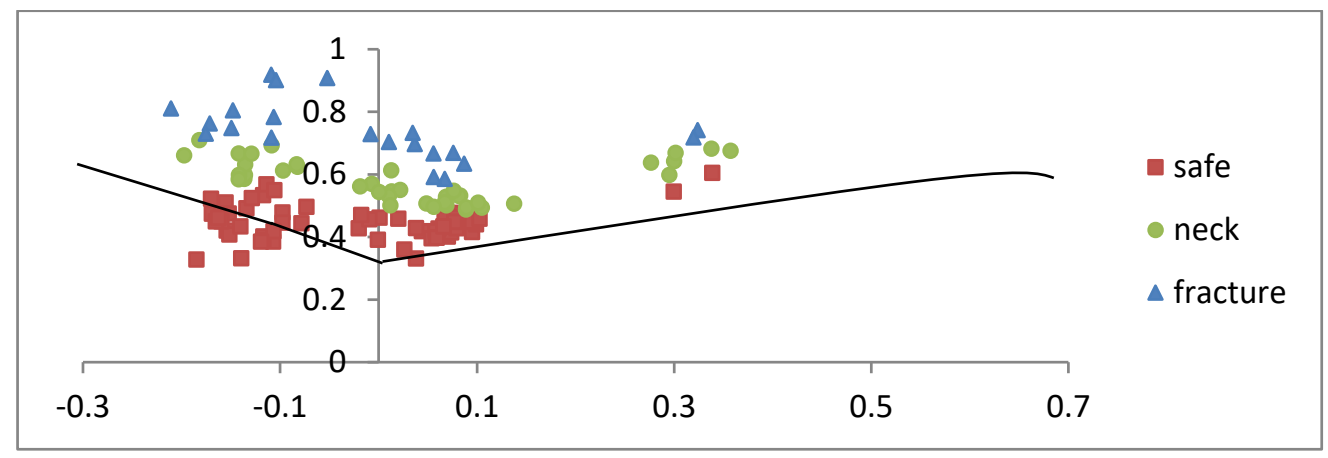

Fig. 4. Forming limit diagram of ASS 304 at RT

\section{LIMITING DOME HEIGHT}

Stretch formability of material is studied based on the Limit Dome Height (LDH). From Table 3 it shows comparison of experimental LDH values with simulation LDH values indicating better LDH in biaxial region for specimen width $70 \mathrm{~mm}$ whereas in plane strain condition for specimen width $50 \mathrm{~mm}$, higher LDH is obtained due to drawing in of the sheet along with stretching which is decreased due to insufficient gripping. Further decrease in blank width below $50 \mathrm{~mm}$, minor strains became negative due to lateral drawing-in and drawing of the sheet is observed. Stretching of $110 \times 110$ specimens in lubricated condition shows higher LDH compared to unlubricated condition.

TABLE 3

COMPARISON OF LDH EXPERIMENTAL AND SIMULATION VALUES OF THE PUNCH-STRETCHED BLANKS OF ASS-304 STEEL FOR VARIOUS BLANK WIDTHS

\begin{tabular}{ccc}
\hline \hline Specimen size & LDH experimental & LDH simulation \\
\hline 110x10 & 23.75 & 24.16 \\
50x110 & 25.64 & 27.34 \\
70x110 & 21.59 & 22.78 \\
90x110 & 19.68 & 21.36 \\
110x110 & 21.29 & 20.4 \\
110x110 lubricated & 24.24 & 26.54 \\
\hline \hline
\end{tabular}

\section{A. Strain Distribution}

Strain distribution profiles in stretching for all the width sizes at room temperature were shown in Figure 5 and represents two distinct peaks in major strain for all the blank width and these peaks were located symmetrically on either side of the pole (the center of the ellipse that is lying exactly below the punch is referred to as pole and it is also the region which has undergone minimum amount of deformation). The asymmetry observed in the magnitude of strain peaks on either side of the pole could be due to the fact that when fracture initiated on one side of the pole, the load ceased to act on the other side which was in either safe or necked zone and hence the deformation did not proceed further in that region [Date and Padmanabhan
(1992)]. In case of minor strain, a similar trend was observed for blank widths $110 \mathrm{~mm}$ to $70 \mathrm{~mm}$ which fall in biaxial stretching mode. For blank width $50 \mathrm{~mm}$, the minor strain is almost zero indicating plane strain condition. In this condition the formability was observed to be minimum as indicated by lower peak strains and lower cup height at failure. Below a blank width of $70 \mathrm{~mm}$, the stretching component decreases in tangential direction (draw bead diameter being $72 \mathrm{~mm}$ ) due to decreased gripping. So the minor strains progressively go down. When the blank width was decreased to below $50 \mathrm{~mm}$, minor strains became negative due to lateral drawing-in and with further decrease in blank width, the minor strains developed two peaks with negative values. This is due to change in stress state from biaxial tension to tension- 
compression (tension in the longitudinal and compression in the transverse directions). As the blank width decreased, the separation between the two peaks
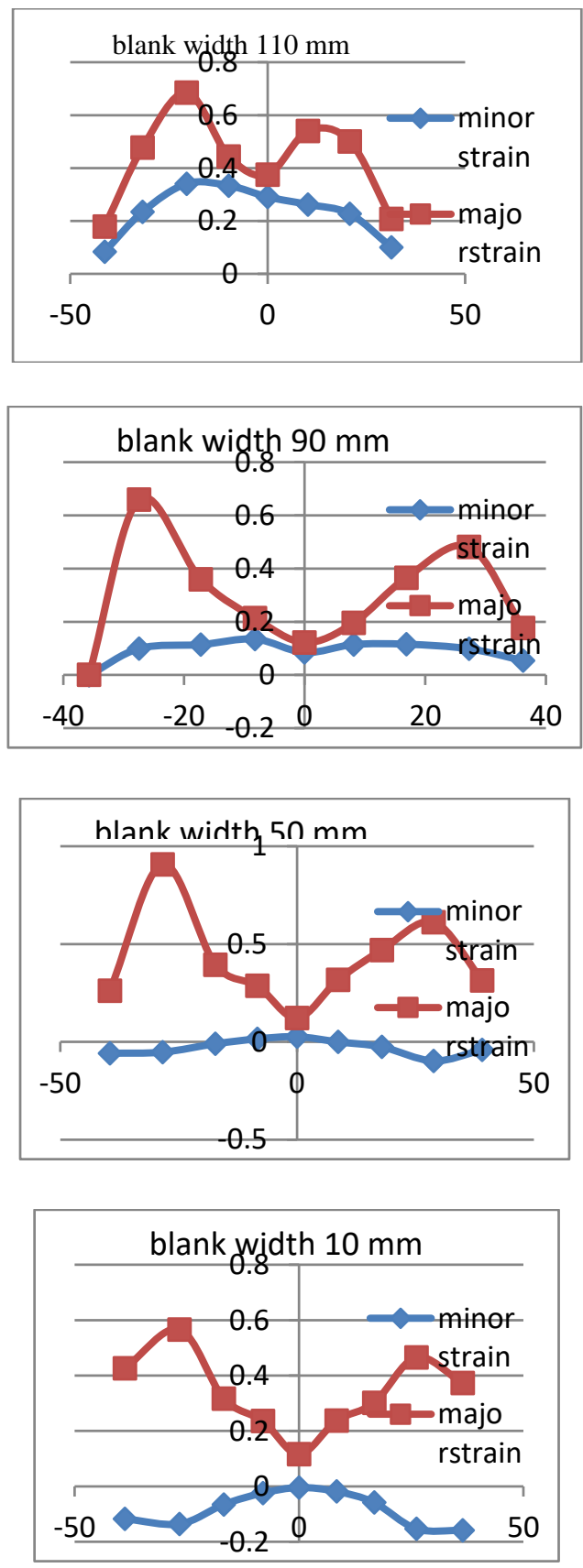

increased progressively because of the increased lateral drawing-in of the sheet metal and correspondingly the failure site also moved away from the pole.
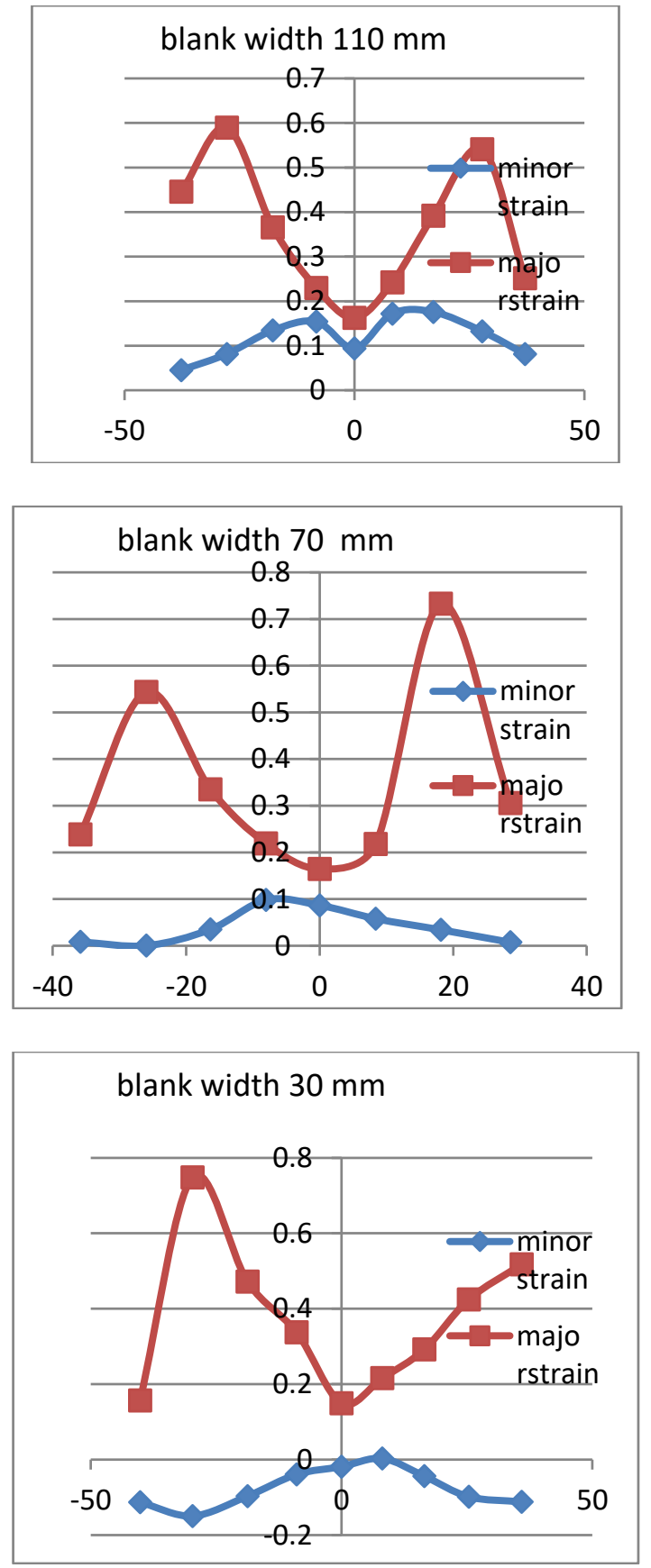

Fig. 5. Longitudinal strain distribution profiles in the punch-stretched blanks of ASS-304 steel for various blank widths

\section{B. Strain Ratio}

The strain ratios (ratio between the minor strain at necked region and major strain at necked region) were calculated for necked ellipses and a plot has been drawn between the strain ratio and blank width. The strain ratio also indicates the formability of the sheet metal. The bar 
graph plotted in Figure 6 shows that when the blank width increases, the strain ratio is positive. When the blank width is less than $50 \mathrm{~mm}$, the strain ratio is negative for all sheets. They correspond to deep drawing region.

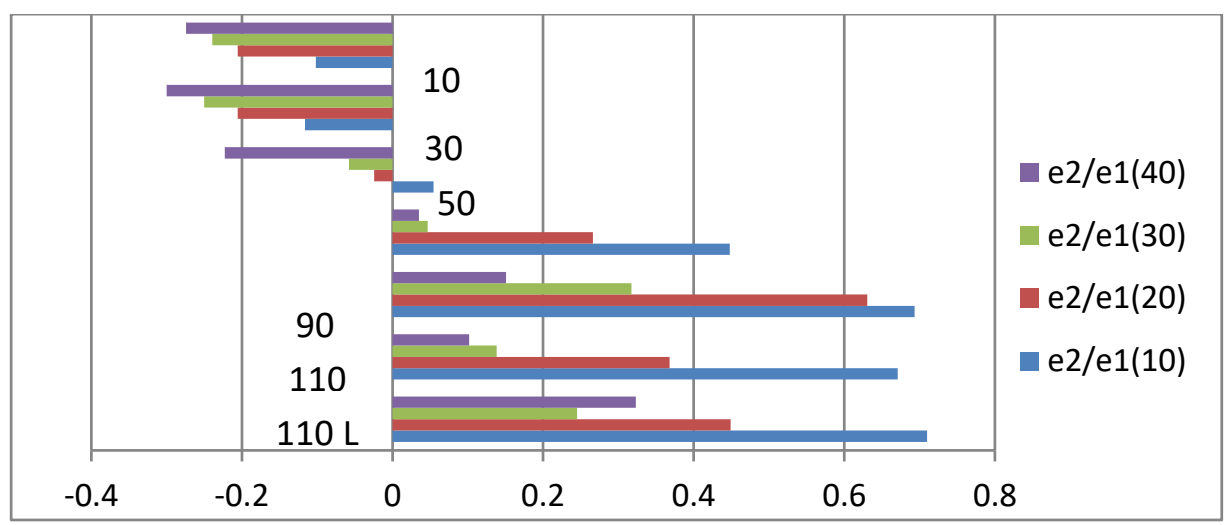

Fig. 6. Variation of limiting strain ratio with respect to specimen width and lubricant condition

\section{CONCLUSIONS}

This work involves experimental and FE analysis of stretching process for ASS-304 at room temperature. The important findings from this study are:

(a) LDH is to be found for $21.59 \mathrm{~mm}$ for $110 \times 70 \mathrm{~mm}$ blank which is higher compared to other blank widths whereas for blank widths $110 \times 50$ to $110 \times 10$ stretching along with drawing in of sheet takes so many LDH results.

(b) The forming limit diagram of ASS 304 obtained by simulation is in good agreement with experimental results. The designation of permissible limit strains provides a measure of forming severity and description of strain distribution that indicates the efficiency of the forming operation or how well potential forming of the sheet was utilized.

\section{ACKNOWLEDGMENT}

Authors would like to thank Department of Science and Technology (DST) Government of India, for providing grant to carry our research activities at the host institute (GRIET) SR/S3/MERC/0129/2012.

\section{REFERENCES}

[1] A. K. Gupta, V. K. Anirudh and S. K. Singh, "Constitutive models to predict flow stress in austenitic stainless steel 316 at elevated temperatures," Journal of Materials and Design, vol. 43, pp. 410-418, 2013. DOI: 10.1016/j.matdes.2012.07.008
[2] S. M. Hussaini, S. K. Singh and A. K. Gupta, "Experimental investigation of dynamic strain aging regime in austenitic stainless steel 316," International Journal of Engineering Research \& Technology, vol. 2, no. 8, pp. 1691-1694, 2013.

[3] S. K. Singh and A. K. Gupta, "Comparison of ironing in warm and hydro-mechanical deep drawing of low carbon steel," Materials Science Forum, vol. 773-774, pp. 203-210. DOI: 10.1016/j.jksues.2012.12.006

[4] L. Jayahari, P. V. Sasidhar, P. P. Reddy, B. BaluNaik, A. K. Gupta and S. K. Singh, "Formability studies of ASS 304 and evaluation of friction for Al in deep drawing setup at elevated temperatures using LSDYNA," Journal of King Saud University-Engineering Sciences, vol. 26, no. 1, pp. 21-31, 2014.

[5] J. K. Wessel, Handbook of Advanced Materials. Hoboken, NJ: John Wiley \& Sons, Inc.

[6] H. I. Medellín-Castillo, P. D. J. García-Zugasti, D. F. de Lange and F. J. Colorado-Alonso, "Analysis of the allowable deep drawing height of rectangular steel parts," The International Journal of Advanced Manufacturing Technology, vol. 66, no. 1-4, pp. 371380, 2013. DOI: $10.1007 / \mathrm{s} 00170-012-4331-9$

[7] A. K. Gupta, H. N. Krishnamurthy, Y. Singh, K. M. Prasad and S. K. Singh, "Development of constitutive models for dynamic strain aging regime in austenitic stainless steel 304," Materials \& Design, vol. 45, pp. 616-627, 2013. DOI: 10.1016/j.matdes.2012.09.041 
[8] H. Takuda, K. Mori and N. Hatta, "The application of some criteria for ductile fracture to the prediction of the forming limit of sheet metals," Journal of Materials Processing Technology, vol. 95, no. 1, pp. 116-121, 1999. DOI: 10.1016/S0924 0136(99)00275-7
[9] T. Iguchi and T. Ujiro, "Effect of imposing temperature gradient in stretch forming process for ferritic stainless steel sheets," in Proceedings of 10th International Conference on Numerical Methods in Industrial Forming Processes, 2010, pp. 1193-1200. DOI: 10.1063/1.3457518

- This article does not have any appendix.- 